\title{
Patients' satisfaction towards medical services at the emergency department of European Gaza Hospital- Gaza Strip
}

\author{
Hammoda Abu-Odah ${ }^{1 *}$, Akram Abu Salah², Ali El-Khateeb ${ }^{3}$, Khawla El-Nems ${ }^{4}$ \\ 'Department of Emergency, European Gaza Hospital, Gaza Strip, occupied Palestinian Territory \\ 2Palestine College of Nursing, El-Fukhari, Gaza Strip, occupied Palestinian Territory \\ ${ }^{3}$ Nursing and Health Sciences Department, University Collage of Applied Sciences, Gaza Strip, occupied Palestinian Territory \\ ${ }^{4}$ Medical Military Rafah Clinic, Medical Services Directorate, Gaza Strip, occupied Palestinian Tterritory
}

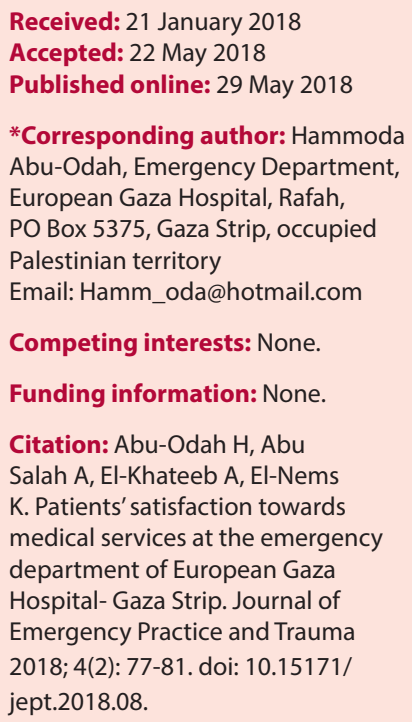

\begin{abstract}
Objective: Patients' satisfaction (PS) is recognized as an important emergency department service design and it has received a high interest and attention in the health management where many studies have focused on determining factors affecting PS in health-related circumstances. In this study, we aimed to examine PS in emergency department (ED) of the European Gaza Hospital (EGH) in the Gaza Strip (GS).

Methods: A descriptive-analytical cross sectional study was performed at ED-EGH between March, 15 and June 20, 2015. Press Ganey questionnaire was used as a tool for data collection. For each patient, a self-administered questionnaire including 22 questions was filled based on a Likert scale. Results were analyzed using SPSS version 22.

Results: Overall, 200 respondents were included in the study. About $73 \%$ of respondents were satisfied with overall medical services. The term of nurses' concern provided to patients elicited the highest score (83.1\%), followed by physicians' concern with patients (72.0\%) and communication skills with patients $(71.4 \%)$, while the lowest score was reported in waiting time and security staff. Furthermore, our findings show an association between PS and level of education, gender differences, living area, and work shifts.

Conclusion: The study results conclude that areas of medical and nursing care, respects of staff, physical comfort and waiting time ED-EGH is highly acceptable and offer in appropriate manners.

Keywords: Patients' Satisfaction, Emergency care, Emergency department, European Gaza Hospital
\end{abstract}

\section{Introduction}

Quality of health care is a worldwide concern that is experiencing a quick revolution to meet needs and demands of the patients'. Hospitals are changing their perception of patients as illiterate, with little or no selected health care; to educated ones with many service requests and health care options available (1). Therefore, respecting the requirements of patients is vital for any health care system. Traditionally, quality of care services is based on professional standards of practice, but in the past decade; it is based on the patient who is an important indicator to measure care services in order to improve performance and effectiveness of clinical perception (2).

PS is an important principle for assessing quality of health care services (3) and it is a current concern in health care management. It has been recognized as a personal assessment of services received against expectations during care (4). In an emergency department (ED), patients' satisfaction (PS) is recognized as an important health care indicator of quality health system, but it is difficult to measure it not only because of the clinical care but also non-clinical care outcomes such as patient expectations about services $(5,6)$. The patient expectations of the services provided to him in the ED are different from the services provided in any hospital departments. This is closely related to emergency medicine, because changes in health care policy and the availability of a physician have been overwhelmed by ED with a patient load that often exceeds their capacity. With increasing waiting periods for accessing emergency services, it is likely that PS presumably suffers. Physicians and health care managers have become increasingly concerned with the patient to meet rapid care and quality expectations. Patients' judgments of the quality of health care services are 
important factors regarding monitoring and promotion (7).

PS is assessed based on a wide range of scopes; as well as availability, accessibility suitability, technical competence of health care providers, interpersonal skills, and the physical environment in which services are provided $(8,9)$. Demographic and clinical characteristics of the patient are also associated with the degree of satisfaction more than the technical quality of care provided (10).

In Palestine, providing a high quality of health services is one of the priorities of the Ministry of Health and one of the Health Sector Strategic Plan for improving the delivery of healthcare services. In this regard, policy-makers need to understand the patient and the institution characteristics as factors that determine health care satisfaction (11). In spite of numerous published studies concerning PS with health services provided in hospitals $(12,13)$, but based on our knowledge, few studies have been conducted to assess PS in the ED. The European Gaza Hospital (EGH) is the second largest hospital in Southern Gaza Strip (GS) and one of the famous teaching hospitals intended to provide high quality of care. Despite importance of PS in the field of scientific research in general and especially in the health fields, the satisfaction is still incomplete. Therefore, this study aimed to evaluate the satisfaction of patients receiving health care services in the ED at EGH in the GS.

\section{Methods}

This descriptive-analytical cross sectional study was designed to examine PS in the ED of EGH. Two-hundred patients, aging over 12 years, treated in the ED between March 15, 2014 and June 20, 2015, were approached to be an element in the sample. The response rate was very high (98\%) and data were obtained from 200 patients. All patients were informed about the study purpose and procedures. Informed consent was obtained as well. The researcher informed participants about the research purpose and the confidentiality of information was quaranteened. In addition, patients were informed about their rights to withdraw or to refuse participation. Completion of each questionnaire took about 20 minutes on average. Furthermore, administrative approval was obtained from General Director of the European Gaza Hospital.

The researcher used the Press Ganey Institute satisfaction questionnaire (14) for evaluating patient satisfaction in the ED with modification of some items due to the Palestine's situation. There was five options for answering to each question based on Likert scale ranging from 1 (very poor) to 5 (very good) (15).

Data were analyzed using SPSS software version 22 . For continuous variables, we used mean and standard deviation. The score of patients' overall satisfaction was considered as the primary outcomes of this study. A chi-squared test was used to determine the association between the variables examined. A regression analysis was used to identify factors affecting PS. A $P$ value less than 0.05 was considered significant.

\section{Results}

About $51.5 \%$ of the patients were younger than 30 years, and $28.0 \%$ were between $30-50$ years. Approximately, $53 \%$ of patients were male, and $47.0 \%$ were female. The results also indicated that $30 \%$ of the 200 participants in the study had a tertiary education level. This means that the majority of the study group is educated. Moreover, findings revealed that $39.5 \%$ of the patients had arrived in the morning shift. Only $24.5 \%$ of participants had visited the ED for receiving services for the first time. Almost 78\% of the patients were discharged from the ED. Nearly $72 \%$ of the patients visited ED for mild medical reasons, where only $6 \%$ visited ED for emergency situations. Thirty-five percent of the 200 participants in the study who filling the questionnaire are patients. Most of attendance to ED

Table 1. The demographic, socio economic and health characteristics of patients $(n=200)$

\begin{tabular}{|c|c|c|}
\hline Variables & No. & Percent \\
\hline \multicolumn{3}{|l|}{ Gender } \\
\hline Male & 106 & 53.0 \\
\hline Female & 94 & 47.0 \\
\hline \multicolumn{3}{|l|}{ Age group (y) } \\
\hline Less and equal 30 years & 103 & 51.5 \\
\hline $31-50$ years & 56 & 28.0 \\
\hline More than 50 years & 41 & 25.5 \\
\hline \multicolumn{3}{|l|}{ Educational level } \\
\hline Primary and less & 41 & 20.5 \\
\hline Secondary & 45 & 22.5 \\
\hline Tertiary & 60 & 30.0 \\
\hline University & 54 & 27.0 \\
\hline \multicolumn{3}{|l|}{ Time visit } \\
\hline Morning & 79 & 39.5 \\
\hline Evening & 75 & 37.5 \\
\hline Night & 23 & 23.0 \\
\hline \multicolumn{3}{|l|}{ Patient first visit here } \\
\hline Yes & 49 & 24.5 \\
\hline No & 151 & 75.51 \\
\hline \multicolumn{3}{|l|}{ Reason for visit } \\
\hline Medical & 95 & 47.0 \\
\hline Surgical & 36 & 18.5 \\
\hline Orthopedic & 69 & 34.5 \\
\hline \multicolumn{3}{|l|}{ IIIness severity } \\
\hline Mild & 144 & 72.0 \\
\hline Moderate & 44 & 22.0 \\
\hline Sever & 12 & 6.0 \\
\hline \multicolumn{3}{|c|}{ Who completed the questionnaire } \\
\hline Patient & 70 & 35.0 \\
\hline Another one & 130 & 65.0 \\
\hline \multicolumn{3}{|l|}{ Living area } \\
\hline Rafah & 86 & 43.0 \\
\hline Bani-Suhila & 114 & 57.0 \\
\hline \multicolumn{3}{|l|}{ Patient's disposition } \\
\hline Discharge & 156 & 78.0 \\
\hline Admission & 44 & 22.0 \\
\hline
\end{tabular}


living in Bani-Suhila area which account 57\%. Table 1 summarizes the demographics of the respondents.

Despite insignificant differences between the 2 groups $(P=0.278)$, results showed that seventy three percent of participants were satisfied with the overall care provided in the ED compared to $17 \%$ who were dissatisfied. A high level of satisfaction was observed for these items: care providers genuine interest (87.5\%), friendliness/ courtesy of the nurse $(83.3 \%)$, efficiency of triage system $(78.5 \%)$ and friendliness/courtesy of the physician (74.0\%). Furthermore, the highest satisfaction rates were observed in the domain of nurses' concern with patients (83.1\%), while physicians' concern with patients and communication skills with patients were $72 \%$ and $71.4 \%$ respectively (Table 2 ).

Satisfaction of patients with the morning shift was the highest in comparison with evening and night shifts (74.3\%, $71.8 \%$ and $73.1 \%$, respectively). Although the overall dissatisfaction rate for the evening shift was less than that for other shifts, there was no significant statistical difference among the different shifts.

About $76.6 \%, 69.9 \%, 75.9 \%, 71.6 \%$ and $73.1 \%$ of the study participants were illiterate, primary, secondary, tertiary, and university level, respectively. Dissatisfaction levels among them were $14.2 \%, 21.0 \%, 14.9 \%, 19.3 \%$ and $16.6 \%$, respectively. Advanced analysis revealed that participants with primary education levels were more dissatisfied
$(P=0.026)$ in comparison with other groups.

In regard to the severity of the patient conditions, their satisfaction with the mild, moderate and severe pain were $73.5 \%, 72.6 \%$ and $71.0 \%$, respectively. Their dissatisfaction levels were $17.4 \%, 18.2 \%$ and $19.8 \%$, respectively.

Although the dissatisfaction rate among males was slightly decreased that for females, there was significant statistical difference among the different gender. This difference was favor for females.

Table 3 demonstrates logistic regression analysis of factors affecting PS. Significant predictors as revealed by multivariate logistic regression analysis showed that educational level remained associated with overall satisfaction $(P=0.002)$. The association between overall satisfaction, age, gender, visit time, and person who completed questions did not reach a statistically significant level $(P=0.14,0.18,0.50,0.68$ respectively $)$.

\section{Discussion}

Patient satisfaction is the most important indicator to measure the quality of health care services and its delivery in the $\operatorname{ED}(7,16,17)$. This report study is the first published study in Palestine focusing on satisfaction using the Press Ganey questionnaire-Arabic version which has an excellent reliability and validity. Our study revealed a high satisfaction level, even though there are numerous unmet needs $(18,20)$. About $73.1 \%$ of 200 respondents of

Table 2. Satisfaction level of clients in regard to 22 items of the questionnaire

\begin{tabular}{|c|c|c|c|c|c|}
\hline Question & Very poor & Poor & Fair & Good & Very good \\
\hline Satisfied with the medical care provided in the ED & 2.5 & 10.5 & 20.5 & 49.0 & 17.5 \\
\hline Triage arrange patients and prevented crowded & 0.0 & 11.5 & 10.0 & 49.0 & 29.5 \\
\hline Care providers genuine interest with the patients & 3.5 & 3.0 & 6.0 & 54.5 & 33.0 \\
\hline Allow to say everything that think is important & 0.0 & 13.0 & 33.5 & 35.0 & 18.5 \\
\hline Information the care provider gave you about medications & 2.0 & 9.5 & 38.0 & 41.0 & 9.5 \\
\hline Instructions the care provider gave you about follow-up care & 4.5 & 7.0 & 26.5 & 51.5 & 10.5 \\
\hline $\begin{array}{l}\text { Degree to which care provider talked with you using words you could } \\
\text { understand }\end{array}$ & 0.0 & 2.5 & 39.0 & 47.5 & 11.0 \\
\hline Get emergency care without any trouble & 4.5 & 13.5 & 34.0 & 35.5 & 12.5 \\
\hline Courtesy of staff in the registration area & 0.5 & 7.0 & 21.5 & 54.0 & 17.0 \\
\hline Easy to get medical care in ED & 0.0 & 10.5 & 25.5 & 46.5 & 17.5 \\
\hline Comfort and pleasantness of the waiting area & 6.5 & 9.5 & 25.5 & 46.0 & 12.5 \\
\hline Courtesy of security staff & 4.5 & 14.0 & 26.5 & 42.5 & 12.5 \\
\hline Waiting for a long time in the triage (unnecessarily) before entering the ED & 4.5 & 24.0 & 30.5 & 17.0 & 24.0 \\
\hline Friendliness/courtesy of the nurse & 0.0 & 4.0 & 12.5 & 45.5 & 38.0 \\
\hline Concern the nurse showed for doing medical orders & 0.0 & 2.5 & 25.0 & 47.0 & 25.5 \\
\hline Comfort and pleasantness during examination & 1.0 & 2.0 & 28.0 & 46.5 & 22.5 \\
\hline Friendliness/courtesy of the physician & 0.5 & 1.0 & 24.5 & 45.0 & 29.0 \\
\hline Explanations the physician gave you about your condition & 3.5 & 3.5 & 28.0 & 50.0 & 15.0 \\
\hline Concern the physician showed for your questions or worries & 1.5 & 10.5 & 29.0 & 47.5 & 11.5 \\
\hline Physician efforts to include you in decisions about your treatment & 7.5 & 5.0 & 34.5 & 35.0 & 18.0 \\
\hline Frequency of being visit by physicians & 5.0 & 12.5 & 31.0 & 33.0 & 18.5 \\
\hline Degree to which physician talked with you using words you could understand & 9.0 & 26.5 & 29.5 & 21.5 & 13.5 \\
\hline
\end{tabular}


Table 3. Logistic regression used for factors affecting on patient satisfaction

\begin{tabular}{|c|c|c|c|c|c|}
\hline Variables & B & Wald & OR & $95 \% \mathrm{Cl}$ & $P$ value \\
\hline Age & 0.42 & 2.15 & 0.65 & $0.37-1.15$ & 0.14 \\
\hline Gender & 0.54 & 1.75 & 1.73 & $0.76-3.90$ & 0.18 \\
\hline Educational level & 0.55 & 9.84 & 0.57 & $0.40-0.81$ & 0.002 \\
\hline Person complete question & 0.28 & 0.45 & 0.75 & $0.32-1.73$ & 0.50 \\
\hline Time of visit & 0.10 & 0.10 & 0.90 & $0.54-1.49$ & 0.68 \\
\hline Constant & 4.35 & 8.47 & 78.00 & & 0.004 \\
\hline
\end{tabular}

our study were satisfied with the overall care. In a report in 2009 it was shown that $83.18 \%$ of 1399047 patients treated at 1725 hospitals nationwide were satisfied with the overall health care (14).

The ED is a unique ward among other medical care services, therefore, understanding the factors affecting PS is essential (17). Thus, the researchers in addition to the satisfaction level, looked for other factors affecting PS by conducting a regression analysis. The study indicated that patients with a high educational level have higher satisfaction level, this is because higher education level participants can listen and converse with the medical staff. Nonetheless, there was no relationship reported by age, gender, work shifts, severity of the patient conditions, and patients who completed the questionnaire. This finding is not in line with the study of Damghi et al that observed an association between satisfaction and type of emergency admission, waiting time and the distance from patient's home to the hospital (21).

Further analysis of data revealed that patients who arrived in the ED between 14:00 to 20:00 were more dissatisfied than those who arrived in the other times of the day and the difference between arriving time and satisfaction level did not reach a significant level. This result is consistent with a Press Ganey report that recorded the highest levels of satisfaction with the ED in early morning hours (14). Evidence shows that age and gender do not have an effect on the satisfaction level $(17,22)$, but there is an association between satisfaction and respect of doctors and nurses for patients during waiting time (17). Another study conducted in Iran confirms the association between gender, level of education and satisfaction (23). Contrary to other researches, our findings showed that gender has an effect on PS.

A study at Cooper Hospital in New Jersey in 2004 showed that the level of satisfaction was the highest in those with serious diseases or urgent needs (24). This result is inconsistent with our findings.

Based on our findings, there are some problems for patients in the ED which need urgent attention to increase patient satisfaction. For example, waiting time and explanation of test results are problems which have an effect on satisfaction. For instance, waiting long time of the patient in triage area of patients who does not need immediate intervention by the medical staff leads to dissatisfaction with the health service
Communication of staff with patients and caregivers and information provided to them are also considered another problem and does not seem to be priority of patients visiting the ED. Here we focus on chronic patients who are reluctant to ED for receiving treatment or admission to hospital. These patients are not concern about health providers communication and information.

This may be attributed to Palestinian's culture. Islam is a major religion in Palestine. The certainty that fate is under the control of Allah and therefore the wellbeing and disease are undeniable. Patients pray to tackle the stressful situations they are faced and win the blessing of Allah. The disease is considered as a predestined fact and should not be directly linked to a possible failure in the management of medical and paramedical situations.

\section{Conclusion}

The simplest, cheapest and most effective way of evaluating health care services is PS. In this study, PS is evaluated and findings show that patients were more satisfied from ED services. Findings reveal that crucial interventions are needed in areas including physician and nursing services, communication skills, registration, physical comfort, and security staff. To achieve these improvements, quality management in health services is essential, and the systematic use of comments and feedbacks can improve efficiency and satisfaction.

\section{Ethical issues}

This study was approved ethically by in-services education department of European Gaza Hospital. Informed consent was taken from the participants for the study.

\section{Authors' contributions}

All authors have read and approved the manuscript. AAS, AEK, and AEN performed the data collection, writing, critical revision and drafting of the manuscript. $\mathrm{HAO}$ undertook the major parts of the study design and performed the statistical analysis, data analysis and data interpretation.

\section{References}

1. Nguyen Thi PL, Briancon S, Empereur F, Guillemin F. Factors determining inpatient satisfaction with care. Soc Sci Med 2002; 54(4): 493-504.

2. Woodring S, Polomano RC, Haagen BF, Haack MM, Nunn RR, Miller GL, et al. Development and testing of patient satisfaction measure for inpatient psychiatry care. J Nurs 
Care Qual 2004; 19(2): 137-48.

3. Goldwag R, Berg A, Yuval D, Benbassat J. Predictors of patient dissatisfaction with emergency care. Isr Med Assoc J 2002; 4(8): 603-6.

4. Sitzia J, Wood N. Patient satisfaction: a review of issues and concepts. Soc Sci Med 1997; 45(12): 1829-43.

5. Trout A, Magnusson AR, Hedges JR. Patient satisfaction investigations and the emergency department: what does the literature say? Acad Emerg Med 2000; 7(6): 695-709.

6. Agarwal D. Health sector reforms: Relevance in India. Indian J Community Med 2006; 31(4): 220-2.

7. Boyer L, Francois P, Doutre E, Weil G, Labarere J. Perception and use of the results of patient satisfaction surveys by care providers in a French teaching hospital. Int J Qual Health Care 2006; 18(5): 359-64. doi: 10.1093/intqhc/mzl029.

8. Grogan S, Conner M, Norman P, Willits D, Porter I. Validation of a questionnaire measuring patient satisfaction with general practitioner services. Qual Health Care 2000; 9(4): 210-5. doi: 10.1136/qhc.9.4.210.

9. Marcinowicz L, Chlabicz S, Grebowski R. Patient satisfaction with healthcare provided by family doctors: primary dimensions and an attempt at typology. BMC Health Serv Res 2009; 9: 63. doi: 10.1186/1472-6963-9-63.

10. Hall JA, Dornan MC. Patient sociodemographic characteristics as predictors of satisfaction with medical care: a meta-analysis. Soc Sci Med 1990; 30(7): 811-8.

11. Palestinian Ministry of Health. Health National Strategic Plans, 2014-2016. 2014. http://info.wafa.ps/pdf/Health_ Strategic_Plan_2011_-_2013.pdf.

12. Al-Kariri N. Patients' satisfaction with the quality of services at the outpatient department of Al-Shifa Hospital [Unpublished Master of Public Health Thesis]. Palestine: Al-Quds University; 2010.

13. Elkahtib Z. Patients' satisfaction with the noncommunicable diseases services provided at UNRWA health centres in Gaza governorates: a cross-sectional study. Lancet 2018; 391 (Suppl 2): S52. doi: 10.1016/S01406736(18)30418-5.
14. Press Ganey Associates, Inc. Guide to Interpreting Calculation of Scores. South Bend: Press Ganey Associates, Inc; 2010.

15. Likert R. A Technique for the Measurement of Attitudes. Arch Psychol 1932; 22(140): 55.

16. Powell L. Patient satisfaction surveys for critical access hospitals. Boise, Idaho: Mountain States Group, Inc; 2001.

17. Hall MF, Press I. Keys to patient satisfaction in the emergency department: results of a multiple facility study. Hosp Health Serv Adm 1996; 41(4): 515-32.

18. Soufi G, Belayachi J, Himmich S, Ahid S, Soufi M, Zekraoui A, et al. Patient satisfaction in an acute medicine department in Morocco. BMC Health Serv Res 2010; 10: 149. doi: 10.1186/1472-6963-10-149.

19. Bleich SN, Ozaltin E, Murray CK. How does satisfaction with the health-care system relate to patient experience? Bull World Health Organ 2009; 87(4): 271-8.

20. Bredart A, Mignot V, Rousseau A, Dolbeault S, Beauloye $\mathrm{N}$, Adam V, et al. Validation of the EORTC QLQ-SAT32 cancer inpatient satisfaction questionnaire by self- versus interview-assessment comparison. Patient Educ Couns 2004; 54(2): 207-12. doi: 10.1016/s0738-3991(03)00210-6.

21. Damghi N, Belayachi J, Armel B, Zekraoui A, Madani N, Abidi K, et al. Patient satisfaction in a Moroccan emergency department. Int Arch Med 2013; 6: 20. doi: 10.1186/17557682-6-20.

22. Aragon SJ, Gesell SB. A patient satisfaction theory and its robustness across gender in emergency departments: a multigroup structural equation modeling investigation. Am J Med Qual 2003; 18(6): 229-41. doi: $10.1177 / 106286060301800603$.

23. Shaikhi MR, Javadi A. Patients' satisfaction of medical services in Qazvin educational hospitals. J Ghazvin Univ Med Sci 2004; 7(5): 62-6. [In Persian].

24. Boudreaux ED, Friedman J, Chansky ME, Baumann BM. Emergency department patient satisfaction: examining the role of acuity. Acad Emerg Med 2004; 11(2): 162-8. 